\title{
Study on Design and Test of Composite WIG Vehicle Considering on Impact Loading
}

\author{
Hyunbum Park $^{1, *}$ \\ ${ }^{1}$ Department of Defense Science \& Technology - Aeronautics, Howon University, 54058, 64 Howondae 3gil, Impi, Gunsan, \\ Rep. of Korea
}

\begin{abstract}
This study proposed an example on preliminary structural design including trade-off study and design evaluation such as structural safety and stability analysis of a 20 -seat composite WIG craft using the netting rule and the rule of mixture and a commercial FEM tool. The structural configuration of the wing adopted the skin-spar semi-monocoque type structure with foam sandwich, and the fuselage also used the semi-monocoque type structure with the skin to carry shear flow, the stringers to carry bending moments and the ring frames to carry local loads under consideration of various design local load cases. The used materials were Carbon/Epoxy (UD) for wing spar flanges and fuselage stringers and ring frames, Carbon/Epoxy (Fabric) for fuselage skins, the sandwich with Carbon/Epoxy face sheet (Fabric) and Al honeycomb core for the fuselage floor, and the sandwich with Carbon/Epoxy face sheet (UD) and Urethane foam core for wing skins and spar webs. Through the structural analysis, the structural safety and stability were confirmed.
\end{abstract}

\section{Introduction}

When a wing is closely flying to the ground or to the water surface within a couple of meters height, the lift force is greatly increased due to the ground-effect. Therefore, if a vehicle uses the wing having the ground effect, it is called a WIG (Wing-in-Ground Effect) craft. The WIG craft has a special feature, which has much wider wings than the traditional airplane wing and the hull type fuselage like a high-speed boat. The WIG craft borrows some merits from both airplane and ship, which can transport quickly many passengers or heavy payload. Since 1960, various types of WIG crafts have been vigorously developed by Russia for military or civil use $[1,2]$.

In Korea, recently studies on the WIG craft are lively progressing as a new generation maritime transportation system. For instance, KORDI (Korea Ocean Research \& Development Institute) and some relating industries have developed several classes of WIG crafts such as the 4seat, 6-seat and 20-seat small-scale WIG crafts and the 100-ton payload large-scale WIG craft.

This study carried out a preliminary structural design and analysis on wing, fuselage and control surfaces parts of the 20-seats small-scale WIG craft. Structural configuration adopted the skin-spar type structure with foam sandwich for the wing, and the semi-monocoque type structure with the skin to carry shear flow, the stringers to carry bending moments and the ring frames to carry local loads under consideration of various design local load cases for the fuselage. The used materials were Carbon/Epoxy (UD) for wing spar flanges and fuselage stringers and ring frames, Carbon/Epoxy (Fabric) for fuselage skins, the sandwich with Carbon/Epoxy face sheet (Fabric) and Al honeycomb core for the fuselage floor, and the sandwich with Carbon/Epoxy face sheet (UD) and Urethane foam core for wing skins and spar webs. The initial design was performed using the netting rule and the rule of mixture. Structural safety and stability evaluation on the design features was done by a commercial FEM code NASTRAN. Through several modifications, the final structural design features were obtained to meet the design requirements such as the system target weight, structural safety and stability.

\section{Concept of Design and Analysis}

The WIG craft to be treated in this study has a similar aerodynamic configuration to the fixed mid-wing airplane. For instances, upper and lower sections of the fuselage have an airplane configuration for reducing the air drag and a boat's hull configuration for reducing the water drag, and the wing is attached to the middle of the fuselage. The tail fins have a ' $\mathrm{T}$ ' shape that the horizontal tail was vertically attached to the vertical fin. Because the WIG craft has an airplane like behaviour after taking-off, therefore load analysis must be firstly performed. For instance, the major design loads become shear forces and bending moments due to the aerodynamic lift and drag, the structural weight and the payload due to passengers and cargo under consideration of the maximum load factor in flight operation, and the impact load at landing. After load case analysis, the

Corresponding author: swordship@daum.net 
fuselage structure can be sized from the major design loads using selected composite materials [3].

After an initial design using the netting rule and the rule of mixture, structural analysis is firstly performed to confirm the structural safety and stability using a commercial FEM code PATRAN/NASTRAN. From the structural analysis on the first design configuration, some modifications can be drawn due to weak area on buckling and a bit heavier than the target weight. The final structural configuration is fixed through several repeated design modifications and analyses.

\section{Impact Load and Structural Design}

The splash down impact load can be defined as the quasi-static impact loads in nose, center (normal landing case) and tail direction, respectively. According to the previous study, it was found that the maximum load among the three cases of the splash down loads was the center body splash down landing case. However, at stress analysis step, all three splash down impact loads were considered. The quasi-static load splash down landing load can be expressed by the following equations:

$$
\begin{gathered}
A_{\text {impact }}=9 \times 10^{-3} M_{\max }^{2 / 3} \\
P^{e}=\frac{F^{e}}{A_{\text {impact }}} \\
F^{e}=n^{e} M_{\text {reduction }} g
\end{gathered}
$$

where $P^{e}$ is pressure on impact area, $A_{\text {impact }}$ - impact area, $F^{e}$-impact load, $n^{e}=1,5-$ impact load factor, $M_{\text {reduction }}$ is reduction coefficient and $g$ is gravitational acceleration[4].

Table 1 shows investigated impact load using the equations. The structural configuration was initially composed of 'I' type front spar and channel type rear spar including flange and web to avoid complexity of manufacturing of the selected Carbon/Epoxy composite laminate.

Table 2 show mechanical properties of carbon/epoxy UD prepreg and carbon/epoxy fabric prepreg. Preliminary structural design was initially performed by the netting rule and the rule of mixture $[5,6]$. According to the netting rule, the principal load directional thickness of main spar flange and web can be sized by the crippling buckling strength.

In order to investigate the structural safety, the initial design feature of the fuselage was modelled as surfaces from the 3-D CATIA drawings after confirmation of detail configurations such as joint parts, spars, ring frames and so on. In the numerical structural analysis of the WIG fuselage, the static stress analysis, the structural stability analysis and the modal analysis were performed using a commercial FEM code PATRAN/NASTRAN. The applied failure theory for safety evaluation was the well-known Tsai-Wu failure criteria. Total number of elements for FEM mesh generation were 35546 including 19080 for the fuselage skin mesh. Fig. 1 shows
FEM modelling result. Figures 2-4 and Table 3 show structural analysis result.

The required 20 years fatigue life of the final design feature was confirmed using the S-N diagram based on the reference carbon/epoxy materials $[7,8]$. If WIG craft may operate with the following assumption such as 12 times 1-hour flight per a day, total number of flights during 20 years can be calculated as 87,600 times. If the safety factor of 3 may be considered, the total number of flights can be modified as 262800 flights. Therefore, the required mission fatigue cycles of 262800 for 20 years operation is less than the given material fatigue life at the same stress level, the designed structure may be safe for the required fatigue life.

Table 1. Landing impact loading of fuselage.

\begin{tabular}{|c|c|c|}
\hline \begin{tabular}{|cc} 
& Material \\
\end{tabular} & $\begin{array}{l}\text { Carbon/ } \\
\text { epoxy } \\
\text { UD }\end{array}$ & $\begin{array}{l}\text { Carbon/ } \\
\text { epoxy } \\
\text { fabric }\end{array}$ \\
\hline Longitudinal modulus (GPa) & 145 & 63,4 \\
\hline Transverse modulus (GPa) & 10 & 58 \\
\hline Axial shear modulus $(\mathrm{GPa})$ & 4,8 & 56,1 \\
\hline Poisson's ratio & 0,25 & 0,17 \\
\hline Longitudinal tensile strength (MPa) & 1240 & 635 \\
\hline $\begin{array}{l}\text { Longitudinal compressive } \\
\text { strength }(\mathrm{MPa})\end{array}$ & 1240 & 572,9 \\
\hline Transverse tensile strength (MPa) & 41 & 411,7 \\
\hline Transverse compressive strength (MPa) & 170 & 304,4 \\
\hline In-plane shear strength (MPa) & 80 & 114,5 \\
\hline Density $\left(\mathrm{kgf} / \mathrm{mm}^{3}\right)$ & $1,58 \mathrm{E}-6$ & $1,58 \mathrm{E}-6$ \\
\hline Thickness (1Ply) (mm) & 0,14 & 0,2 \\
\hline
\end{tabular}

\begin{tabular}{|c|c|c|c|}
\hline Load & Case 1 & Case 2 & Case 3 \\
\hline$P^{e}$ & $33 \mathrm{kN} / \mathrm{m}^{2}$ & $43 \mathrm{kN} / \mathrm{m}^{2}$ & $42 \mathrm{kN} / \mathrm{m}^{2}$ \\
\hline$F^{e}$ & \multicolumn{3}{|c|}{$124 \mathrm{kN}$} \\
\hline$A_{\text {impact }}$ & $3,75 \mathrm{~m}^{2}$ & $2,92 \mathrm{~m}^{2}$ & $2,92 \mathrm{~m}^{2}$ \\
\hline
\end{tabular}

Table 2. Mechanical properties of carbon/epoxy composite

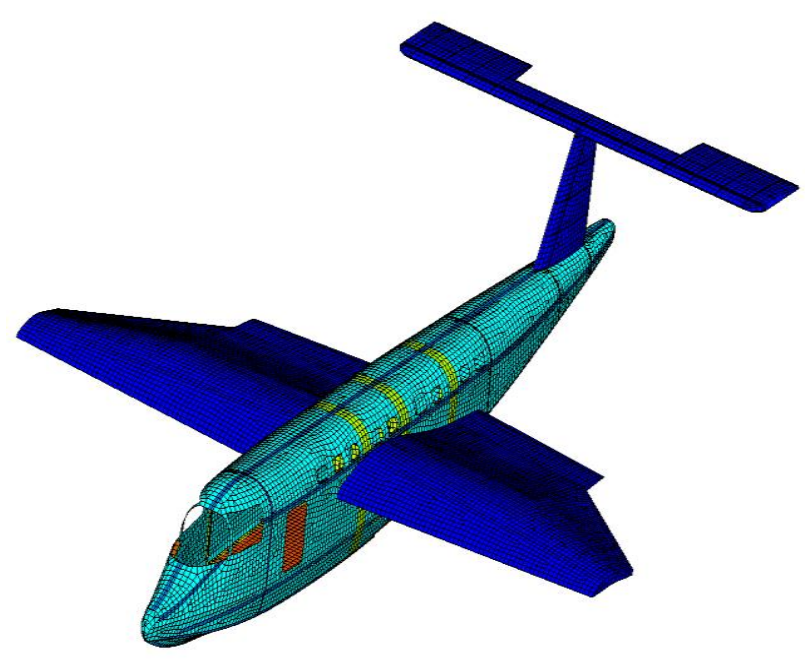

Figure 1. Mesh generation for finite element analysis. 


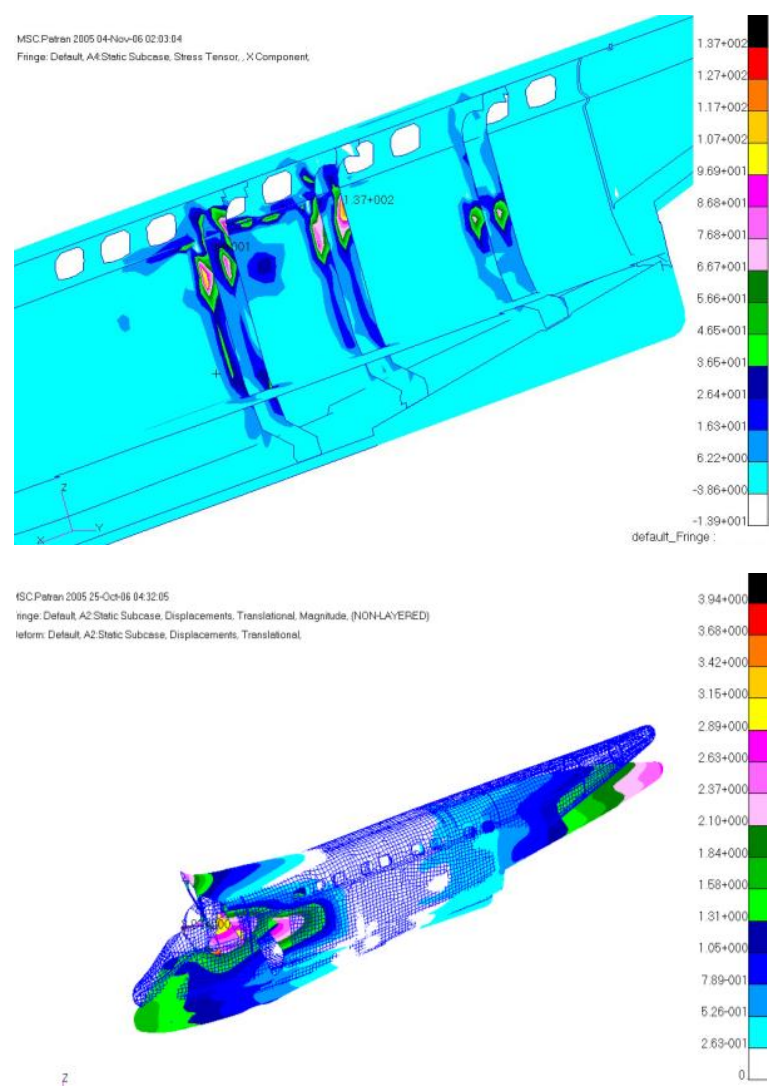

Figure 2. Stress contour and deformed shape of fuselage in load case 1 .

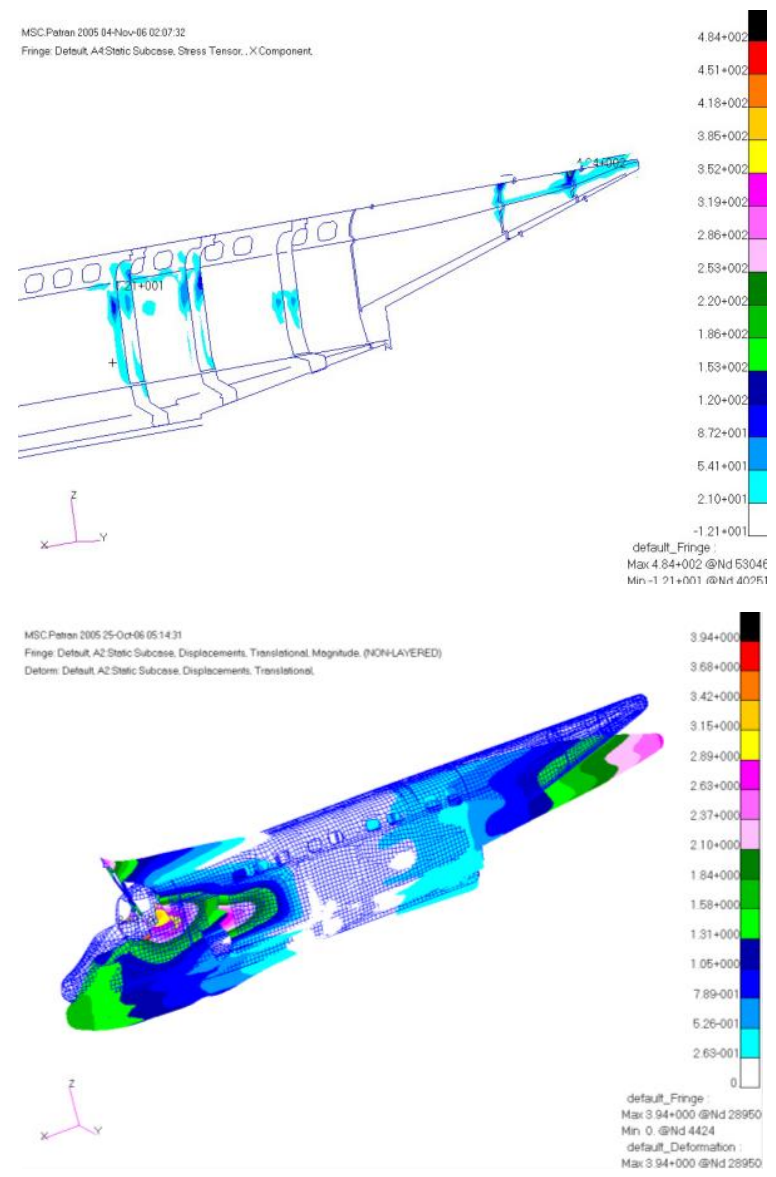

Figure 3. Stress contour and deformed shape of fuselage in load case 2 .

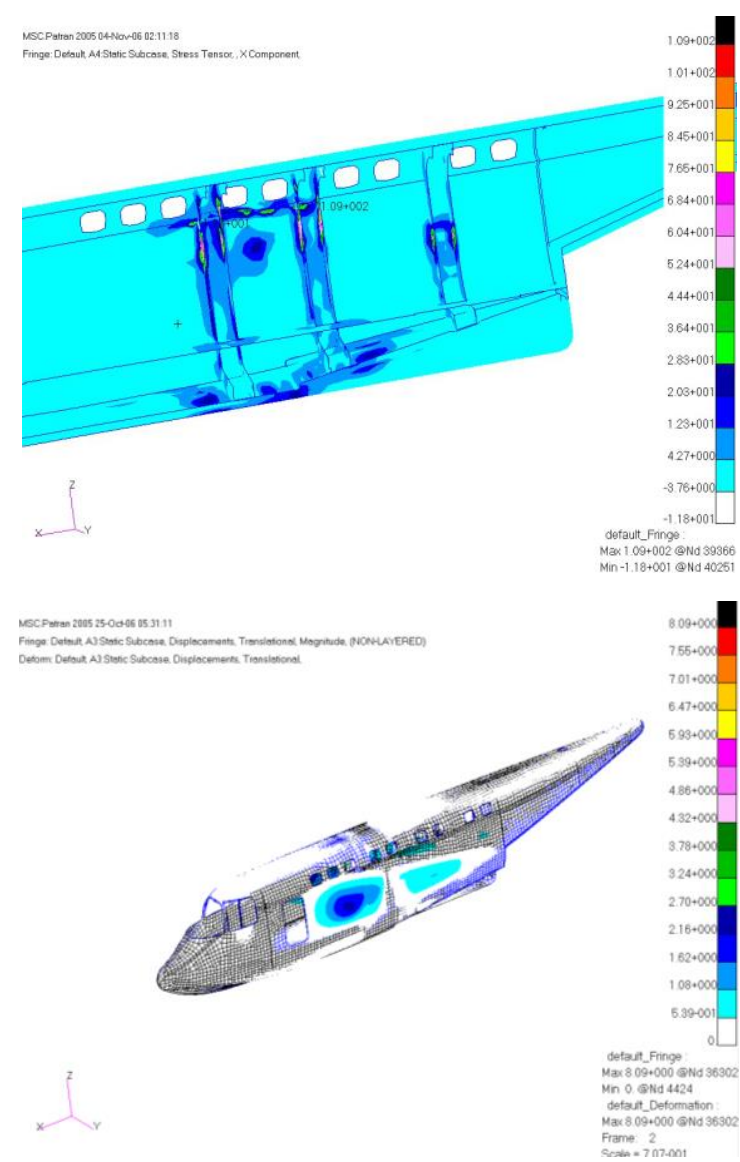

Figure 4. Stress contour and deformed shape of fuselage in load case 3 .

Table 3. Structural Analysis Results.

\begin{tabular}{|c|c|c|c|c|}
\hline \multicolumn{2}{|c|}{$\begin{array}{c}\text { Case of analysis } \\
\text { Analysis result }\end{array}$} & $\begin{array}{c}\text { Symmetric } \\
\text { Load } \\
\text { (Case 1) }\end{array}$ & $\begin{array}{c}\text { Un-symmetric } \\
\text { load } \\
\text { (Case 2) }\end{array}$ & $\begin{array}{c}\text { Splash } \\
\text { Down } \\
\text { (Case 3) }\end{array}$ \\
\hline $\begin{array}{c}\text { Max. } \\
\text { stress, } \\
\text { MPa }\end{array}$ & Ten. & 137 & 484 & 109 \\
\cline { 2 - 5 } & Com. & 135 & 694 & 117 \\
\hline \multicolumn{2}{|c|}{ Max. disp., mm } & 3.84 & 3.94 & 8.9 \\
\hline
\end{tabular}

\section{Manufacturing and Test}

A 6-seat WIG craft was developed as a subscale to minimize the development risk of the 20 -seat WIG craft by KORDI-MOERI (Korea Ocean Research \& Development Institute- Maritime and Ocean Engineering Research Institute), HANKUK FIBER CO. and others including authors. Table 4 shows the system specification of the 6-seat WIG craft and Figures 5-7 shows some views for manufacturing and flight test.

After an initial design using the netting rule and the rule of mixture, structural analysis is firstly performed to confirm the structural safety and stability using a commercial FEM code PATRAN/NASTRAN. From the structural analysis on the first design configuration, some modifications can be drawn due to weak area on buckling and a bit heavier than the target weight. The final structural configuration is fixed through several repeated design modifications and analyses. Before manufacturing the full scale the prototype, the structural 
test and flight test was performed by a sub-scale WIG craft for evaluation of the proposed structural design and analysis procedure. Through this comparison, even though there were some differences between them, it was confirm that the proposed design method is appropriate for the WIG's composite structure.

Table 4. System specification of 6-seat WIG Craft.

\begin{tabular}{|c|c|}
\hline Length & $12 \mathrm{~m}$ \\
\hline Pay Load & 6 passengers \\
\hline Gross Weight & $1200 \mathrm{~kg}$ \\
\hline Maximum Speed & $137 \mathrm{~km} / \mathrm{h}$ \\
\hline Engine Power & $2 \times 102 \mathrm{hp}$ \\
\hline Material & $\begin{array}{c}\text { Carbon } / \text { Epoxy laminates }+\mathrm{Al} \\
\text { honeycomb core sandwich }\end{array}$ \\
\hline
\end{tabular}

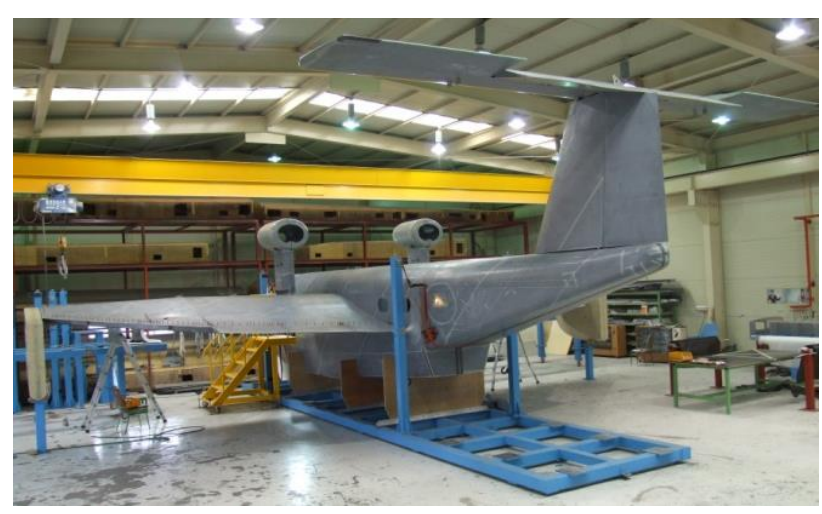

Figure 5. Combination wing and fuselage of WIG craft.

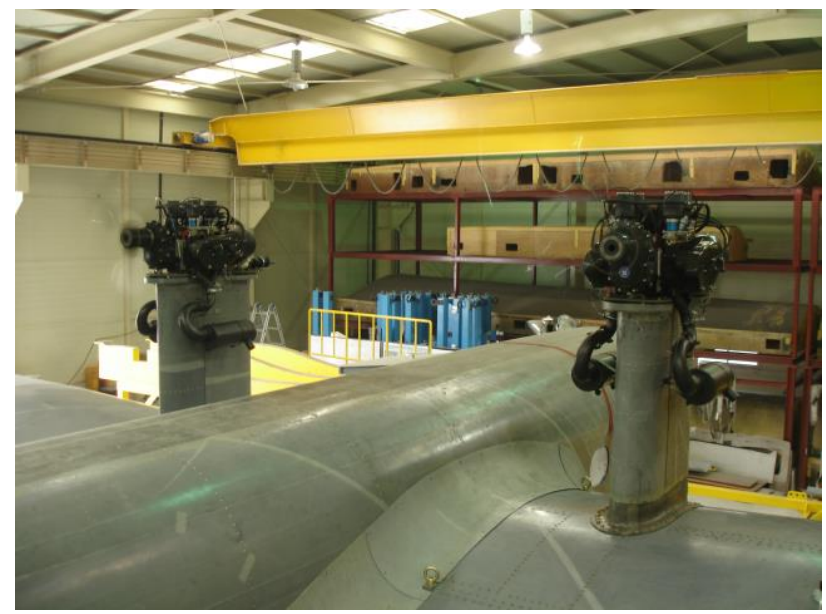

Figure 6. Engine thrust test of WIG craft.

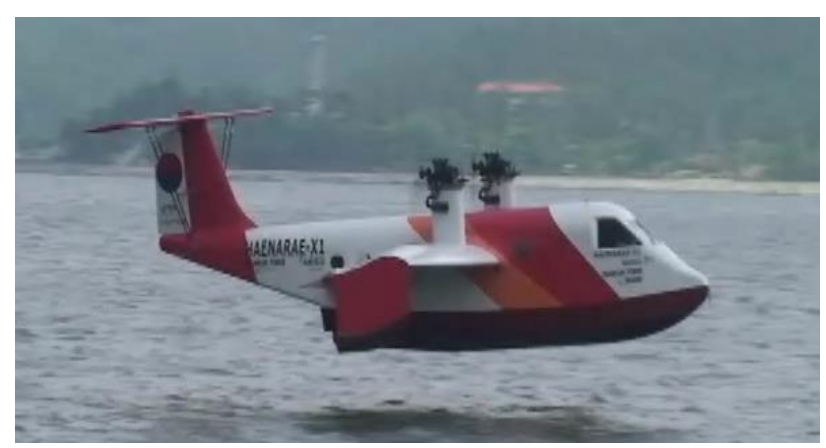

Figure 7. Flight test of 6-seat WIG craft.

\section{Conclusion}

In this study a composite WIG craft structure, which can satisfy the target weight as well as the structural safety and stability, was designed. Basic structural feature adopted the skin-spar type structure, and especially the foam sandwich composite was applied to upper and lower skins of the wing to improve buckling behavior and vibration absorption capability. The front spar adopted 'I' type beam and the rear spar adopted channel type beam to accommodate control surface structure. In order to improve the strength/weight ratio as well as the stiffness/weight ratio the carbon/epoxy composite material which is mostly used in aerospace vehicle design was selected.

The fuselage was designed by a semi-monocoque type structure with the skin to carry shear flow, the stringers to carry bending moments and the ring frames to carry local loads under consideration of various design load cases. The used materials were the carbon/epoxy laminates using the UD prepreg for stringers and ring frames and the fabric prepreg for the skin and the sandwich structure with Al alloy core and Carbon/Epoxy fabric face sheet for the floor.

Through the static stress analysis including the structural stability analysis, the fatigue life estimation and the modal analysis, the final design WIG craft structural feature with the required 20 years fatigue life and the proper vibration characteristics was confirmed.

\section{Acknowledgements}

This study was supported by research fund from KORDI (Korea Ocean Research \& Development Institute), Hankuk Fiber and Howon University.

\section{References}

1. K. Rozhdestvensky, Wing-in-ground effect vehicles, Progress in aerospace sciences, 42 (2006)

2. N. Kornev, K. Matveev, Complex numerical modeling of dynamics and crashes of wing-inground-vechicles, AIAA 2003-600 (2003)

3. C. Kong, Structural investigation of composite wind turbine blade considering various cases and fatigue life, Energy 30 (2005)

4. B. Lee, C. Kim, M. Park, H. Jeong, ALE finite element analysis of the WIG craft under the water impact loads, Journal of the Korean society for aeronautical and space science 35 (2007)

5. S. Tsai: Composites Design, Think Composite, (1987)

6. M. Niu: Airframe Structural Design, Hong Kong Conmilit Press Ltd, (1988)

7. V. Vasiliev, E. Morozov, Mechanics and analysis of composite materials, Elsevier Science Ltd, (2001)

8. M. Hyer, Stress Analysis of Fiber-Reinforced Composite Materials, WCB/McGraw-Hill, (1998) 